Article

\title{
City-Level Features of Energy Footprints and Carbon Dioxide Emissions in Sichuan Province of China
}

\author{
Junbo Wang ${ }^{1}$, Liu Chen ${ }^{1}$, Lu Chen ${ }^{1}$, Xiaohui Zhao ${ }^{2}$, Minxi Wang ${ }^{1}$, Yiyi Ju ${ }^{3,4, *}$ and Li Xin ${ }^{1, *}$ \\ 1 College of Management Science, Chengdu University of Technology, Chengdu 610051, China; \\ wangjunbo2019@gmail.com (J.W.); chenliusylvia@sina.com (L.C.); 18862671733@163.com (L.C.); \\ wangminxi@mail.cdut.edu.cn (M.W.) \\ 2 Graduate School of Economics, Nagoya University, Nagoya 464-8601, Japan; zhaoxhcufe@163.com \\ 3 Graduate School of International Development, Nagoya University, Nagoya 464-8601, Japan \\ 4 Institute of Future Initiative, The University of Tokyo, Tokyo 113-0033, Japan \\ * Correspondence: aftermath_11@163.com (Y.J.); lixin2012@cdut.cn (L.X.)
}

Received: 26 April 2019; Accepted: 23 May 2019; Published: 27 May 2019

\begin{abstract}
The sustainable development of the western region of China has always been essential to the national development strategy. The Western region has undertaken an industrial transfer from the Eastern and Central regions. Therefore, the $\mathrm{CO}_{2}$ emission intensity in the western region is higher than those of the Eastern and Central regions of China, and consequently its low-carbon development pathway has an important impact for China as a whole. Sichuan Province is not only the province with the highest $\mathrm{CO}_{2}$ emissions, but also the most economically developed province in Western China in 2018. In order to promote low carbon development in the western region, it is important to understand the features of emissions in Sichuan Province and to formulate effective energy strategies accordingly. This paper uses the IPCC regional emission accounting method to calculate the carbon emissions of 15 cities in Sichuan province, and to comply with the city-level emission accounts. The results show that the total carbon emissions of Sichuan province over the past 10 years was $3258.32 \mathrm{mt}$ and reached a peak in 2012. The smelting and pressing of ferrous metals, coal mining and dressing were the leading sectors that contributed to the emissions, accounting for $17.86 \%$ and $15.82 \%$, respectively. Raw coal, cleaned coal, and coke were the most significant contributors to $\mathrm{CO}_{2}$ emissions, accounting for $43.73 \%, 9.55 \%$, and $6.60 \%$, respectively. Following the above results, the Sichuan provincial government can formulate differentiated energy structure policies according to different energy consumption structures and carbon emission levels in the 15 cities. By controlling the level of total emissions and regulating larger industrial emitters in Sichuan province, some useful information could be provided as an essential reference for low-carbon development in Western China, and contribute to the promotion of emissions mitigation from a more holistic perspective.
\end{abstract}

Keywords: energy footprint; Western China; low-carbon development; $\mathrm{CO}_{2}$ emission

\section{Introduction}

Climate change is one of the most severe and complex issues in human history [1,2]. According to the International Energy Agency (IEA) report, the latest statistics show the energy consumption and carbon dioxide emissions related to energy in 2018 both had the fastest growth in this decade. The global energy demand grew by $2.3 \%$ in 2018 , while energy-related $\mathrm{CO}_{2}$ emissions rose by $1.7 \%$, and reached an all-time high of $33 \mathrm{Gt}$. The pressure from the interrelationship between vast amounts of energy usage and carbon emission caused by energy have forced policymakers to undertake action in order to mitigate climate change and achieve low-carbon economic development [3-5]. At present, as the world's largest developing country, China has become the largest energy consumer and the 
largest $\mathrm{CO}_{2}$ emitter in the world [6-8]. In 2012, China's $\mathrm{CO}_{2}$ emissions reached a historical peak $(7.9 \mathrm{Gt})$, accounting for a quarter of global emissions $[9,10]$. With the rapid growth of population and industrialization all over the world, the demand for fossil fuel energy in human activities is increasing, with the use of coal being especially dominant in China. It is the energy consumption characteristics that involve mainly relying on coal that is consequently causing increasingly serious emission problems [11,12].

China is not only geographically divided into three regions, Eastern, Central, and Western regions, but also hosts a significant disparity with respect to economic development and carbon dioxide emissions between the three areas [13]. Although the absolute amount of $\mathrm{CO}_{2}$ emission in western China does not occupy the largest share in the total domestic emissions (i.e., eastern, central, and western China with shares of $44.21 \%, 24.34 \%$, and $31.45 \%$, respectively in 2015 [14]), due to the less developed economy and more local industries with high primary energy use, the emission intensity is the highest ( 1.03 tons $/ 10^{4} \mathrm{CNY}, 1.44$ tons $/ 10^{4} \mathrm{CNY}$ and 1.89 tons $/ 10^{4} \mathrm{CNY}$ in eastern, central, and western China, respectively). Different economic development levels and industrial structures have led to differences in $\mathrm{CO}_{2}$ emissions between the three regions, indicating that the emission reduction strategies of Western China will be unique. An analysis of particular $\mathrm{CO}_{2}$ emission and emission-related energy will contribute to a scientific understanding of energy footprint characteristics, as well as provide essential references for energy transformation and emission reduction strategies.

The Western region covers 12 provinces and municipalities in China, with land area and population accounting for $71.2 \%$ and $32.3 \%$ of China, respectively. Abundant raw resources in this area have attracted much attention from the government and investors alike. Since 2000, the Chinese government have implemented the "western development" strategy which gives priority, financially and politically, to support for the economic development of the Western region. In nearly two decades, the development of infrastructure construction in the West has achieved tremendous success, providing a more conducive environment for economic development. The Belt and Road Initiative also encourages the development of Central and Western China. Western China can take advantage of its geographical position in order to pursue economic cooperation with Central Asia, South Asia, and Southeast Asia. With the help of this policy support and the participation of private capital, the rapid economic development in the Western region resulted in an average annual GDP growth of $8.8 \%$ between 2013-2017. In 2017, the GDP in the Western region was $20.7 \%$ of the national total; however, the total emission mitigation failed to perform as well as its GDP. In 2015, the western region accounted for $31.45 \%$ of $\mathrm{CO}_{2}$ emissions [14], with the highest emission intensity implying an imbalance between economic and environment. Adjusting the development trend in the western region is important and urgent for the emission reduction process in China, as well as the world.

Sichuan Province has the best economic development in the Western region, with the largest proportion of GDP in the Western region reaching 21.6\% in 2015 [13]. Moreover, the total emissions in Sichuan province occupied the largest share of total emissions in Western China (11.8\% in 2015 [14]). In Western China, Sichuan's economic status is promising where mineral resource reserves, population, animal husbandry, fishery production value, industrial added value, the added value of the service industry, investment in fixed assets and the financial industry's total assets have always ranked highest in the country [13]. Therefore, the economic development of Sichuan is not only influential for the Western region but also powerful for whole of China. As for the $\mathrm{CO}_{2}$ emissions in this province, it is better to analyze the emission sources in order to figure out how, and where we need to take actions to reduce the carbon dioxide emissions.

Cities consume two-thirds of the world's energy and contribute more than $70 \%$ of the world's $\mathrm{CO}_{2}$ emissions [15]. When considering the terminal consumption of power, cities consume $71-76 \%$ of total $\mathrm{CO}_{2}$ emissions [16]. With rapid population growth and the acceleration of urbanization, cities are experiencing continuous increases in both energy demand and per capita $\mathrm{CO}_{2}$ emissions [17-19]. China's urban carbon dioxide emissions contribute $85 \%$ of total emissions, higher than the world average, and much higher than developed countries and regions such as Europe (69\%) and the United 
States $(80 \%)$. Therefore, in light of the importance of city-level conditions, the decision-makers and implementers of climate change mitigation policies should pay more attention, and we should conduct more in-depth studies on energy utility and $\mathrm{CO}_{2}$ emissions at the city level [20-23]. Understanding the characteristics of urban energy consumption, establishing an accurate urban carbon dioxide emissions inventory, and investigating the driving factors of $\mathrm{CO}_{2}$ emissions are the primary conditions for implementing climate change mitigation and corresponding measures [24,25]. Detailed carbon emission data revealing the sources of energy can provide technical support and management methods for building low-carbon cities and research into low-carbon development strategies [26]. At present, emission inventories and carbon emission drivers of some national and provincial regions in China have been studied and discussed, such as Liaoning province, Hunan province, southeast coastal areas and northern coastal areas [27-32]. Studies on China's urban-level emission inventory and energy consumption are mostly concentrated in provincial capitals and megacities such as Beijing, Shanghai, Guangzhou, Hong Kong, Tianjin, Nanchang, Chongqing, Shenzhen and the Greater Bay area [24,30,33-40]. At present, few studies have focused on carbon dioxide emissions in western China. This study focuses on Sichuan Province, regarded as the most important province in the Western area, that can provide references for other provinces in the same region in order to understand their energy selection among many industries and sectoral carbon emission, formulate low-carbon development strategies in the economically underdeveloped areas and further help China to make overall national decisions.

In this paper, in order to clarify the features of the energy footprint and related carbon dioxide emissions in Sichuan Province, the carbon emission inventory related to the energy consumption of 15 key cities in Sichuan Province from 2006 to 2015 are quantified based on the Intergovernmental Panel on Climate Change regional emission calculation method [41]. Moreover, the achievement of emission reduction goals in these regions before has also been examined. Such quantification can provide a useful reference for the low-carbon development of Western China, as well as contribute to the promotion of emission mitigation from a more holistic perspective in China.

\section{Methodology}

This study employs the Intergovernmental Panel on Climate Change method (IPCC) regional emission calculation method in order to calculate the $\mathrm{CO}_{2}$ emissions of 15 cities in Sichuan Province from the production side, and with a sectoral approach. The IPCC method assumes that the $\mathrm{CO}_{2}$ emissions inventory is based on two sources: energy consumption and industrial processes. By adopting this method, the carbon dioxide emissions from 47 socioeconomic sectors, 17 fossil fuels, and seven primary industry processes are considered (see Tables S1-S3 in the Supplementary Materials) within the urban boundaries of 15 Chinese cities [5]. Using the same IPCC method, this study analyzes energy consumption more comprehensively. In the investigation, the emissions from the electricity generation industry are calculated only through conventional energy inputs (e.g., raw coal, petrol, and diesel oil). However, the emissions generated from energy and electricity across the city boundaries to other regions are not calculated. In order to avoid the problem of double counting, energy used for chemical materials and that lost during transport are removed from the total energy consumption [42,43].

\subsection{Quantification of Energy Consumption and $\mathrm{CO}_{2}$ Emissions}

Based on the IPCC method, the total carbon emission from one society includes the emissions from different fossil fuels and sectors. Precisely, each sector's emission from one kind of energy is calculated by multiplying the energy activities (energy consumption) and emission factors of the respective socio-economic sector as follows:

$$
C E_{\text {energy }}=\sum_{i=1}^{17} \sum_{j=1}^{47} C E_{i j}=\sum_{i=1}^{17} \sum_{j=1}^{47} A D_{i j} \cdot N C V_{j} \cdot C C_{j} \cdot O_{i j}
$$


where $i$ is the type of energy and $j$ is the socio-economic sector (see Table S1). $C E_{i j}$ represents $\mathrm{CO}_{2}$ emissions of energy type $i$ in the socio-economic sector $j . A D_{i j}$ represents the activity data, using fossil fuel consumption of energy $i$ in sector $j$ as a proxy. $N C V_{j}, C C_{j}$ and $O_{i j}$ are referred to as emission factors, representing the net calorific value, carbon content, and oxidation efficiency from $j$ department or $i$ energy type, respectively. Liu, Guan et al. (2015) deeply investigate the energy consumption in China by employing these three emission factors.

In this study, the main kinds of fossil fuel, i.e., coal, oil, and natural gas, are divided into 17 types. We select 47 sectors as the main development direction in Sichuan Province, based on the industrial sectors classification of the National Economic Accounting System [44]. These 47 divisions can be assorted into four categories. Specifically, there are five energy production-related sectors which generate energy covering the primary and secondary types. Sixteen heavy industry sectors, producing intermediate products, which include ferrous metal ore dressing, non-metallic mineral products and so on. The light industry category covers the food processing sector, furniture manufacturing sector and another 11 sectors producing end products. The last category constitutes the five industries focusing on high and new technologies [18].

\subsection{Industrial Process}

Different industrial processes have different impact levels of carbon emission. In this study, we focus on seven emission-intensive industrial processes, accounting for more than $95 \%$ of China's total process-related emissions [42,45,46]; namely silicon metal, iron, iron-chromium alloys, ammonia, soda ash, cement, and lime processes. It is worth mentioning that $\mathrm{CO}_{2}$ emissions from these industrial processes represent emissions only from chemical reactions; however, they do not consider the energy-specific use in these industries. We can use the following equation to indicate the process-related $\mathrm{CO}_{2}$ emissions calculation:

$$
C E_{\text {process }}=\sum_{t=1}^{7} C E_{t}=\sum_{t=1}^{7} A D_{t} \cdot E F_{t}
$$

where $t$ denotes industrial process, $C E_{t}$ represents the process-related $\mathrm{CO}_{2}$ emissions in process $t$. $A D_{t}$ denotes activity data by proxying production of industrial process $t ; E F_{t}$ is the emission factor in process $t$ provided mainly by the IPCC, while the cement production factor is derived from [47].

\subsection{Uncertainty Analysis}

Uncertainties associated with input and parametric modeling can have potentially significant impacts on the accuracy of carbon dioxide emission estimations [48]. Uncertainties may derive from incomplete data, economic fluctuations, environmental factors, and many implications related to subjective judgments and data quality issues $[49,50]$. Further, uncertainties from emission factors and energy activities also could affect the estimation. Following the recommendation of the IPCC, this study employs the Monte Carlo simulation in order to alleviate the uncertainty. In the Monte Carlo framework, all input parameters regarding activity data and emission factors are assumed as having a normal distribution. In total, 20,000 simulations were conducted to analyze the uncertainty of emissions estimation by socio-economic sector. The coefficients of variations $(\mathrm{CV}$, standard deviation divided by the mean) are adopted from previous research [41,51,52].

\subsection{Examination of the Achievement of Emission Reduction Goal}

Based on the average growth rate of GDP and $\mathrm{CO}_{2}$ emissions in the past 10 years, the emission intensity in Eastern, Central, Western China, as well as Chengdu, Mianyang, and Panzhihua is estimated. The emission intensity in the $n$th year, $C_{n}$, can be formulated as:

$$
C I_{n}=C E_{0}(1+\alpha)^{n} / X_{0}(1+\beta)^{n}
$$


where $C E_{0}$ represents the total emissions of the target region in the benchmark year; $X_{0}$ represents the GDP of the target region in the benchmark year; $\alpha$ represents the annual growth rate of total emissions in the target region, and $\beta$ represents the annual growth rate of GDP in the target region. In this paper, both the benchmark year of emission and GDP are set as 2015; at the same time, both $\alpha$ and $\beta$ are obtained by the moving average value from 2005 to 2015 .

Since the emission reduction goal is set in the form of emission intensity, whether the region in question may achieve the emission reduction goal can be roughly examined.

\subsection{Data Source}

This study selects 15 cities of the 21 urban districts in Sichuan Province because the energy consumption data of these 15 cities are available in the study interval (2006-2015). The GDP of these 15 cities accounts for $85.83 \%$ of the total GDP of Sichuan Province. Moreover, the carbon dioxide emissions from these cities account for even more than $90 \%$ of total emissions in this province. Therefore, it is enough to use these 15 cities to represent the carbon emission of this province. Table 1 provides the socio-economic indicators of 15 key cities in Sichuan Province in 2015.

The annual GDP, population, and GDP per capita data are obtained from the statistical yearbooks of each city. The total carbon dioxide emissions are calculated according to the methods in Section 2.1. It is concluded that the emission intensity is the carbon dioxide emissions per unit of GDP, and the carbon dioxide emissions per capita is the ratio of the total carbon dioxide emissions to the population of the city.

The energy balance sheet, the energy consumption data of industrial sub-sectors, and the output of industrial products are all from the statistical yearbooks of these 15 key cities. The energy consumption data of Ganzi (2006-2007) and Yaan (2006) are not reported in the statistical yearbook, thus some of the carbon dioxide emissions inventories cannot be estimated (Sichuan statistical yearbook, 2006-2016).

Table 1. Emission and socio-economic indicators of 15 cities in Sichuan Province, 2015.

\begin{tabular}{ccccccc}
\hline City & $\begin{array}{c}\text { Population } \\
\left(\mathbf{1 0}^{4}\right)\end{array}$ & $\begin{array}{c}\text { GDP (10 } \\
\text { CNY) }\end{array}$ & $\begin{array}{c}\text { GDP Per } \\
\text { Capita } \\
\text { (CNY) }\end{array}$ & $\begin{array}{c}\text { Total } \\
\text { Emission } \\
\text { (Million } \\
\text { Tons) }\end{array}$ & $\begin{array}{c}\text { Emission } \\
\text { Intensity } \\
\text { (Tons/10 } \\
\text { CNY) }\end{array}$ & $\begin{array}{c}\text { Carbon } \\
\text { Emission } \\
\text { Per Capita } \\
\text { (Tons/Person) }\end{array}$ \\
\hline Chengdu & 1228.05 & $10,801.16$ & $87,953.75$ & 47.46 & 0.44 & 3.86 \\
Mianyang & 473.94 & 1700.33 & $35,876.48$ & 12.22 & 0.72 & 2.58 \\
Panzhihua & 123.20 & 925.18 & $75,095.78$ & 84.39 & 9.12 & 68.50 \\
Deyang & 351.09 & 1605.06 & $45,716.48$ & 7.53 & 0.47 & 2.14 \\
Guangyuan & 305.31 & 605.43 & $19,830.01$ & 17.55 & 2.90 & 5.75 \\
Yibin & 552.08 & 1525.90 & $27,639.11$ & 22.65 & 1.48 & 4.10 \\
Luzhou & 505.68 & 1353.41 & $26,764.16$ & 16.39 & 1.21 & 3.24 \\
Zigong & 327.46 & 1143.11 & $34,908.39$ & 5.90 & 0.52 & 1.80 \\
Leshan & 353.79 & 1301.23 & $36,779.73$ & 39.36 & 3.02 & 11.13 \\
Suining & 378.75 & 915.81 & $24,179.80$ & 13.83 & 1.51 & 3.65 \\
Ganzi & 116.49 & 213.04 & $18,288.27$ & 1.06 & 0.50 & 0.91 \\
Meishan & 349.20 & 1029.86 & $29,491.98$ & 21.11 & 2.05 & 6.05 \\
Neijiang & 420.43 & 1198.58 & $28,508.43$ & 36.18 & 3.02 & 8.61 \\
Yaan & 111.42 & 502.58 & $45,106.80$ & 3.30 & 0.66 & 2.96 \\
Ziyang & 354.72 & 1270.40 & $35,814.16$ & 5.56 & 0.44 & 1.57 \\
\hline
\end{tabular}

\section{Results and Discussion}

\section{1. $\mathrm{CO}_{2}$ Emissions in 15 Key Cities}

The city-level emission accounts for the 2006-2015 period are shown in Table 2 which includes the total carbon dioxide emissions of 15 cities in Sichuan Province. The trends of total emissions in 15 cities indicate they have experienced their peaks and have entered a slow decline phase. It can be 
seen that province-level emission peaked at 406.23 million tons in 2012 and then fell to 334.49 million tons in 2015. The rapid increase phase of Sichuan Province is between 2007-2012 with total carbon dioxide emissions demonstrating an average annual growth rate of $12.31 \%$. In this decade, the carbon dioxide emissions of three cities, Panzhihua, Chengdu, and Leshan, are almost equivalent to one-half of the total emissions in this province. Notably, 2015 contributed the most to the province's carbon dioxide emissions among all 15 cities, accounting for $25.23 \%, 14.19 \%$, and $11.77 \%$, respectively.

Table 2. Total carbon dioxide emissions in 15 key cities in Sichuan Province, 2006-2015 (million tons).

\begin{tabular}{ccccccccccc}
\hline City & $\mathbf{2 0 0 6}$ & $\mathbf{2 0 0 7}$ & $\mathbf{2 0 0 8}$ & $\mathbf{2 0 0 9}$ & $\mathbf{2 0 1 0}$ & $\mathbf{2 0 1 1}$ & $\mathbf{2 0 1 2}$ & $\mathbf{2 0 1 3}$ & $\mathbf{2 0 1 4}$ & $\mathbf{2 0 1 5}$ \\
\hline Chengdu & 21.75 & 33.33 & 31.01 & 34.69 & 40.38 & 42.97 & 42.15 & 41.21 & 48.32 & 47.46 \\
Mianyang & 17.09 & 15.83 & 10.23 & 12.09 & 14.54 & 14.62 & 14.89 & 15.05 & 14.40 & 12.22 \\
Panzhihua & 68.89 & 105.16 & 94.22 & 109.75 & 115.27 & 120.91 & 104.28 & 86.72 & 87.32 & 84.39 \\
Deyang & 6.71 & 8.14 & 7.49 & 8.87 & 10.56 & 10.18 & 10.69 & 9.85 & 9.23 & 7.53 \\
Guangyuan & 6.98 & 9.23 & 7.83 & 8.92 & 10.78 & 16.58 & 18.28 & 13.40 & 13.11 & 17.55 \\
Yibin & 15.85 & 14.37 & 16.00 & 17.06 & 18.61 & 25.38 & 30.30 & 31.60 & 27.38 & 22.65 \\
Luzhou & 15.30 & 16.79 & 17.27 & 21.14 & 23.95 & 32.41 & 23.40 & 16.28 & 17.21 & 16.39 \\
Zigong & 8.00 & 8.18 & 8.05 & 8.85 & 10.59 & 12.14 & 10.72 & 8.18 & 7.31 & 5.90 \\
Leshan & 11.95 & 15.67 & 18.30 & 21.75 & 28.26 & 35.12 & 41.06 & 39.69 & 32.73 & 39.36 \\
Suining & 8.10 & 9.96 & 11.81 & 12.18 & 12.02 & 12.85 & 15.01 & 10.18 & 11.60 & 13.83 \\
Ganzi & - & - & 0.81 & 0.89 & 1.07 & 1.06 & 1.31 & 0.95 & 0.97 & 1.06 \\
Meishan & 11.52 & 13.32 & 15.91 & 17.48 & 19.65 & 21.79 & 24.02 & 23.83 & 22.64 & 21.11 \\
Neijiang & 12.79 & 17.86 & 21.36 & 27.08 & 35.11 & 46.28 & 58.01 & 52.28 & 41.50 & 36.18 \\
Yaan & - & 1.03 & 1.27 & 2.55 & 3.85 & 5.10 & 5.05 & 3.41 & 3.36 & 3.30 \\
Ziyang & 3.46 & 4.85 & 6.04 & 6.42 & 7.17 & 7.27 & 7.06 & 6.11 & 5.88 & 5.56 \\
Total & 208.39 & 273.72 & 267.6 & 309.72 & 351.81 & 404.66 & 406.23 & 358.74 & 342.96 & 334.49 \\
\hline
\end{tabular}

In order to analyze the features of emissions in 15 cities from multiple angles, this paper also analyzes carbon emission intensity and carbon dioxide emissions per capita. According to Figure 1, in 2015, the range of the carbon emission intensity between 15 cities was from 0.44 tons $/ 10^{4}$ CNY (Chengdu) to 9.12 tons $/ 10^{4}$ CNY (Panzhihua). The overall carbon intensity reached a peak of 66.47 tons $/ 10^{4} \mathrm{CNY}$ in 2007. And then the carbon intensity was declining, dropping to 28.05 tons $/ 10^{4}$ CNY in 2015. This peak happened earlier than the carbon dioxide emissions maximum, indicating the economic development decreased the intensity while increasing the amount of emissions. In Sichuan, the economic structures of Ganzi and Chengdu are dominated by services and high value-added industries. Therefore, they have the lowest carbon emission intensity, compared with high-intensity industrial cities, such as Panzhihua, Neijiang, and Leshan. The trend of emissions per capita is similar with the total amount increasing rapidly at an average annual growth rate of $10.79 \%$ between 2007 and 2012, reaching a peak of 173.15 tons/person in 2011, and then starting to slow down with an annual average growth rate of $6.51 \%$.

To further explore the $\mathrm{CO}_{2}$ emissions of cities in Sichuan Province, and to confirm which emission level this province belongs to, a comparison with the average emissions in China will display the difference between this area and the average country level. In 2015, China's total carbon dioxide emissions were 9.78 billion tons [14], with a total GDP of 68,905 billion CNY and a total population of 1.37 billion [13]. It is easy to find that the average emission intensity $\left(1.87\right.$ tons $\left./ 10^{4} \mathrm{CNY}\right)$ of the 15 cities in 2015 is $31.69 \%$ higher than that of China's urban average ( 1.42 tons $\left./ 10^{4} \mathrm{CNY}\right)$. Further, the most significant gap is observed with Panzhihua City having an emission intensity of 9.12 tons $/ 10^{4} \mathrm{CNY}$ which is more than five times of China average (Figure 1). As for the emissions per capita, it also indicates a similar situation to that of the Sichuan province average of 8.84 tons/person, which is 1.24 times the amount of the national average of 7.11 tons/person. Even though two indicators both display a higher level of carbon emission in Sichuan, in fact, these 15 cities have made significant efforts to promote low-carbon development with the help of technological advancement, industrial transformation and the implementation of incentive policies. From 2006 to 2015, the carbon emission intensity decreased from 4.03 tons $/ 10^{4} \mathrm{CNY}$ to 1.87 tons $/ 10^{4} \mathrm{CNY}$, while the national average decreased from 2.78 tons $/ 10^{4}$ 
$\mathrm{CNY}$ to 1.42 tons $/ 10^{4} \mathrm{CNY}$ [14]. With the increase of economic growth and decrease in carbon emission, Sichuan's intensity would be close to the national average emission intensity at this rate.

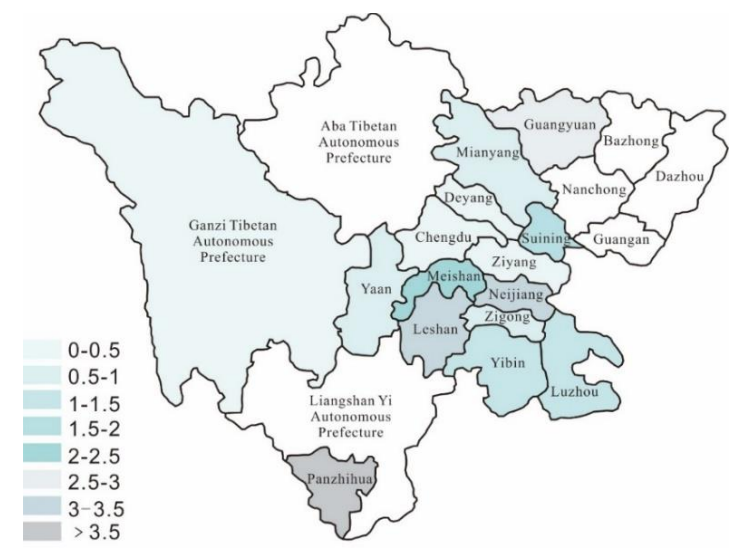

Figure 1. $\mathrm{CO}_{2}$ emission intensities of 15 key cities in Sichuan, 2015 (Unit: tons/10 $\mathrm{CNY}$ ).

\section{2. $\mathrm{CO}_{2}$ Emissions in $15 \mathrm{Key}$ Cities in Terms of Energy Type and Industrial Sectors}

Different types of energy have various uses, and emission amounts also vary by type. Therefore, more detailed information about the energy used in each city could reveal real carbon emitters and would be helpful to inform targeted strategies in order to reduce emissions. Among the target cities, coal and coal-related products (raw coal, washed coal, other coal washing, briquette, and coke) are the main types of energy consumed, followed by petroleum products (crude oil, gasoline, kerosene, diesel and fuel oil).

In 2015, coal-related and oil-related products produced $71.88 \%$ of the total $\mathrm{CO}_{2}$ emissions in Sichuan, of which the emissions from raw coal, clean coal and coke were the top three. During the past ten years, the total emissions from raw coal in these 15 major cities reached a peak of $49.18 \%$ (199.78 Mt) in 2012 and fell to $36.17 \%$ (120.99 Mt) in 2015. The fluctuation of coke emissions is small, and these emissions account for an average of $6.68 \%$ per year. In 2015 , emissions decreased to $5.37 \%$. The contribution rates of gasoline and diesel are quite low but in an increasing trend that is increasing from $0.96 \%$ and $1.62 \%$ to $3.70 \%$ and $3.49 \%$ in these ten years, respectively. Natural gas has a stable share of around $6.70 \%$.

Separating the emissions according to different industrial sectors can also indicate some trends with respect to which industries need more pressure to reduce their carbon dioxide emissions, or which industries have been an excellent example for other industries, or the same industry in other regions. In Sichuan Province, the smelting and pressing of ferrous metals division has had the highest total emissions, with $581.94 \mathrm{Mt}$ of carbon emissions over the past decade, accounting for $21.6 \%$ of the 15 cities. Unlike the gross province trend, this industry still demonstrates a growing trend and reached a peak of $65.56 \mathrm{Mt}$ in 2015. The following sectors with the highest carbon dioxide emissions were nonmetal mineral products, electric power, steam, and hot water production and supply, with contribution ratios of 19.0\%, 15.7\%, respectively (Figure 2). Finally, in Sichuan Province, the secondary industry contributed a maximum of $88.73 \%$, and the tertiary industry shared $10.52 \%$, of which the transportation sector dominated, accounting for $3.57 \%$ of the 15 cities.

Figure 3 displays the circulation map of energy and carbon dioxide emissions in Sichuan Province in 2015. These 17 energy types are invested in primary, secondary and tertiary industries, which are divided into 47 socio-economic sectors, and energy consumption in various sectors produces different amounts of carbon dioxide emission. There are three linkages between the factors worthy of focus. The left one shows how the different types of energy are consumed in three industries; the middle one shows how energy consumption generates carbon dioxide emissions with a more detailed decomposition within the sub-sectors of three departments, and the last relationship, on the right hand side, once again summarizes the carbon emissions into three departments. 


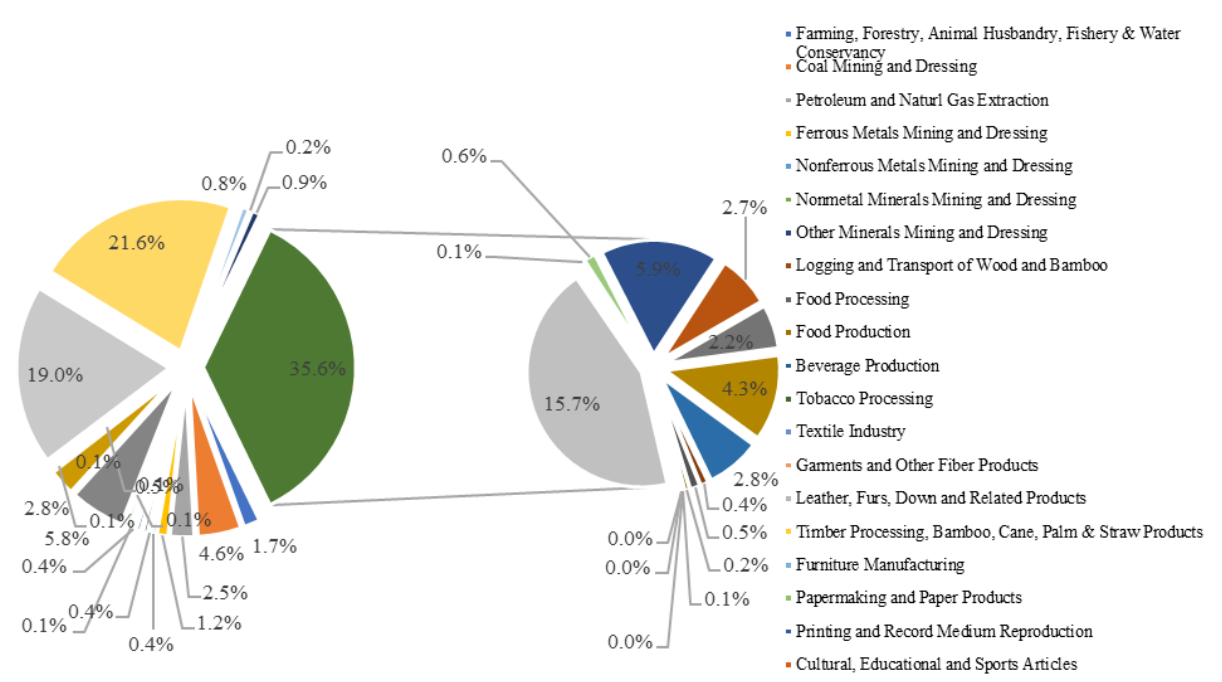

Figure 2. The proportion of carbon dioxide emissions in the industrial sector (Smelting and Pressing of Ferrous Metals, Nonmetal Mineral Products, Electric Supply, 21.6\%, 19.0\%, 15.7\%).

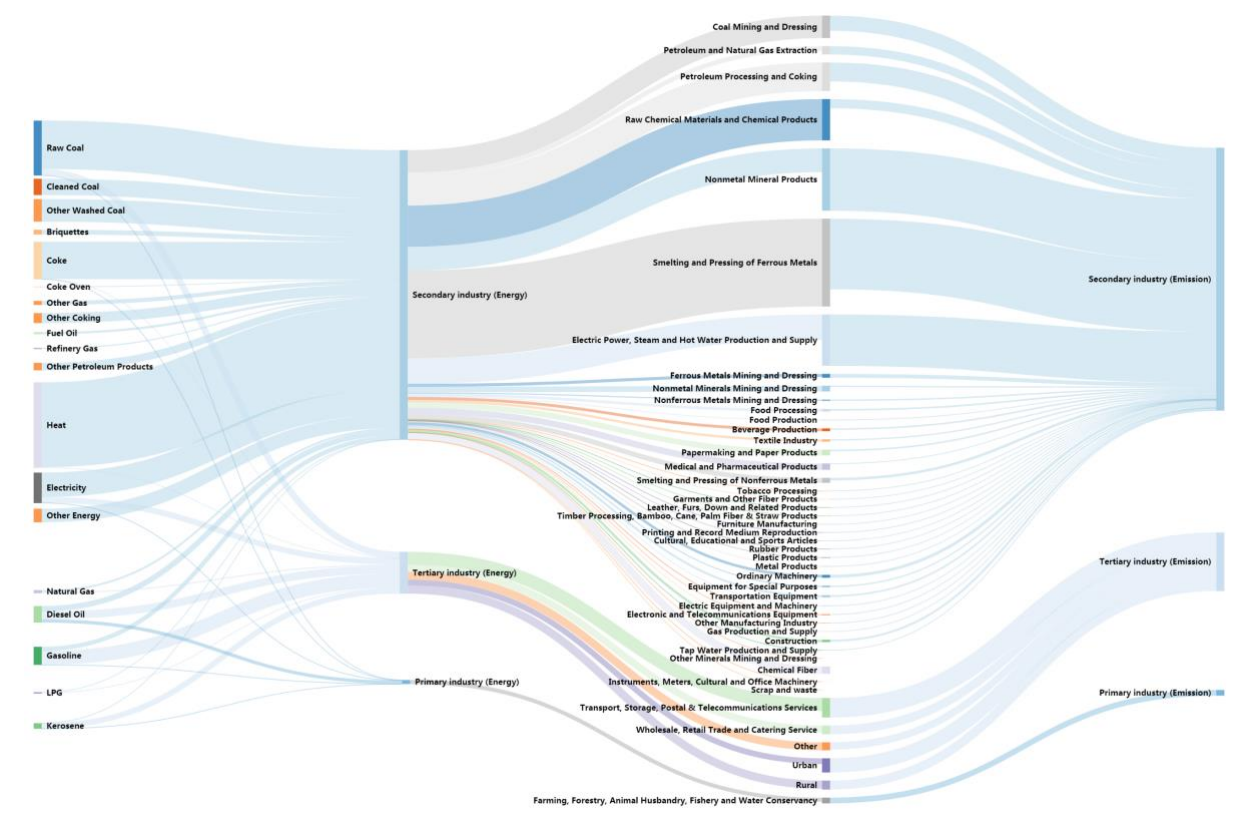

Figure 3. Energy and carbon emission's circulation map of target cities in Sichuan Province, 2015.

As for the sectors, namely the smelting and pressing of nonferrous metals, raw chemical materials, and chemical products, coal mining and dressing, which consume relatively more energy but emit relatively fewer emissions, this is due to a higher dependence on electricity consumption instead of other energy sources such as fossil fuels.

Sichuan Province is a typical region in China with a sufficient capacity of hydropower. The emission intensity of the electricity supply sector in Sichuan has been less than the average level of all regions in China. Therefore, a better understanding of the carbon dioxide emissions contributed by industry, sector and energy type, shown in Table 3, is conducive for the government to develop a low carbon policy. For Sichuan Province, which benefits from an abundant clean electricity supply, it is better to control the energy consumption of the electricity channel and to encourage fossil fuel users to transform their energy selection from higher emission to lower emission electricity (hydropower), by way of innovating their electricity-consuming equipment or machines. The inventory list of the target cities provides data support for the low carbon development plan in Sichuan. 
Table 3. Types of energy consume in 15 key cities in Sichuan Province, 2015.

\begin{tabular}{|c|c|c|c|c|c|c|c|c|c|c|c|c|c|c|c|c|c|c|c|c|}
\hline $\begin{array}{l}\text { Types of } \\
\text { Energy }\end{array}$ & $\begin{array}{l}\text { Raw } \\
\text { Coal }\end{array}$ & $\begin{array}{c}\text { Cleaned } \\
\text { Coal }\end{array}$ & $\begin{array}{c}\text { Other } \\
\text { Washed } \\
\text { Coal }\end{array}$ & Briquettes & Coke & $\begin{array}{c}\text { Coke } \\
\text { Oven } \\
\text { Gas }\end{array}$ & $\begin{array}{l}\text { Other } \\
\text { Gas }\end{array}$ & $\begin{array}{c}\text { Other } \\
\text { Coking } \\
\text { Products }\end{array}$ & $\begin{array}{l}\text { Crude } \\
\text { Oil }\end{array}$ & Gasoline & Kerosene & $\begin{array}{c}\text { Diesel } \\
\text { Oil }\end{array}$ & $\begin{array}{c}\text { Fuel } \\
\text { Oil }\end{array}$ & LPG & $\begin{array}{c}\text { Refinery } \\
\text { Gas }\end{array}$ & $\begin{array}{c}\text { Other } \\
\text { Petroleum } \\
\text { Products }\end{array}$ & $\begin{array}{c}\text { Natural } \\
\text { Gas }\end{array}$ & Heat & Electricity & $\begin{array}{l}\text { Other } \\
\text { Energy }\end{array}$ \\
\hline Unit: & $10^{4}$ tce & $10^{4}$ tce & $10^{4}$ tce & $10^{4}$ tce & $10^{4}$ tce & $\begin{array}{l}10^{8} \\
\mathrm{~m}^{3}\end{array}$ & $\begin{array}{l}10^{8} \\
\mathrm{~m}^{3}\end{array}$ & $10^{4}$ tce & $\begin{array}{l}10^{4} \\
\text { tce }\end{array}$ & 104 tce & $10^{4}$ tce & $10^{4}$ tce & $10^{4}$ tce & $\begin{array}{l}10^{4} \\
\text { tce }\end{array}$ & $10^{4}$ tce & $10^{4}$ tce & $10^{8} \mathrm{~m}^{3}$ & $\begin{array}{c}10^{10} \\
\mathrm{Kj}\end{array}$ & $10^{8} \mathrm{kWh}$ & $10^{4}$ tce \\
\hline Chengdu & 286.2 & 92.6 & 0.4 & 2.7 & 21.9 & 1.5 & 0.0 & 0.0 & 214.3 & 209.5 & 109.6 & 197.5 & 10.4 & 31.9 & 0.6 & 15.4 & 35.3 & 1893.2 & 344.2 & 3.4 \\
\hline Mianyang & 255.9 & 17.4 & 0.0 & 0.0 & 8.3 & 0.0 & 0.0 & 0.0 & 0.2 & 23.9 & 0.3 & 14.0 & 0.0 & 1.1 & 0.0 & 0.3 & 7.1 & 13.9 & 55.7 & 0.0 \\
\hline Panzhihua & 483.6 & 187.5 & 59.4 & 65.6 & 370.6 & 14.2 & 138.8 & 6.1 & 0.0 & 5.3 & 0.0 & 11.5 & 0.1 & 0.3 & 0.0 & 0.8 & 0.5 & 1282.2 & 138.7 & 0.0 \\
\hline Deyang & 192.6 & 0.0 & 0.0 & 0.0 & 9.7 & 0.0 & 0.0 & 0.0 & 0.0 & 16.1 & 0.0 & 13.4 & 0.0 & 0.8 & 0.0 & 0.0 & 14.8 & 0.7 & 88.8 & 0.0 \\
\hline Guangyuan & 145.1 & 60.2 & 0.2 & 40.4 & 1.0 & 0.7 & 0.0 & 0.0 & 0.0 & 11.8 & 0.0 & 6.0 & 0.0 & 0.6 & 0.0 & 0.0 & 5.9 & 0.4 & 41.6 & 0.1 \\
\hline Yibin & 94.6 & 1.9 & 3.6 & $\begin{array}{l}x_{0.7} \\
1.9\end{array}$ & 7.3 & 0.8 & 0.7 & 0.0 & 0.0 & 32.2 & 8.9 & 29.4 & 0.6 & 1.8 & 0.3 & 0.4 & 5.1 & 207.9 & 90.9 & 5.5 \\
\hline Luzhou & 108.9 & 84.9 & 12.6 & 0.0 & 6.2 & 0.2 & 0.4 & 0.0 & 17.6 & 32.0 & 10.9 & 23.6 & 0.2 & 1.9 & 0.1 & 0.0 & 16.0 & 173.3 & 51.4 & 1.5 \\
\hline Zigong & 178.5 & 3.6 & 1.8 & 2.5 & 4.4 & 0.1 & 0.0 & 0.0 & 0.0 & 13.9 & 0.1 & 7.1 & 13.9 & 1.2 & 0.0 & 0.3 & 3.8 & 102.8 & 37.5 & 1.3 \\
\hline Leshan & 238.2 & $\begin{array}{r}3.0 \\
119.3\end{array}$ & $\begin{array}{l}1.0 \\
44.9\end{array}$ & 95.6 & $\begin{array}{c}4.4 \\
142.1\end{array}$ & 0.2 & 43.8 & 0.1 & 20.7 & 24.7 & $\begin{array}{l}.1 \\
7.4\end{array}$ & 26.3 & 0.2 & 1.5 & 0.1 & $\begin{array}{l}0.3 \\
187.7\end{array}$ & $\begin{array}{l}7.0 \\
7.9\end{array}$ & $\begin{array}{l}102.0 \\
66.8\end{array}$ & 182.5 & 2.1 \\
\hline Suining & 68.9 & 18.1 & 0.5 & 0.0 & 4.4 & 0.1 & 0.0 & 0.0 & 48.1 & 22.8 & 3.4 & 18.7 & 0.0 & 1.4 & 0.0 & 26.4 & 11.7 & 208.1 & 165.0 & 0.2 \\
\hline Ganzi & 34.8 & 0.0 & 1.0 & 0.0 & $\begin{array}{l}0.2 \\
0.1\end{array}$ & 0.2 & 0.0 & 0.0 & 0.0 & 8.5 & 1.6 & 6.9 & 0.2 & 0.5 & 0.1 & 0.1 & 0.4 & 0.0 & 10.0 & 1.5 \\
\hline Meishan & 123.2 & 35.1 & 7.9 & 15.2 & 13.0 & 0.1 & 0.0 & 0.3 & 11.4 & 14.1 & 4.1 & 13.5 & 0.0 & 0.0 & 0.0 & 0.1 & 6.7 & 203.7 & 86.7 & 20.0 \\
\hline Neijiang & 249.9 & 1.4 & 0.4 & 0.0 & 0.8 & 0.1 & 0.0 & 0.0 & -0.8 & 25.2 & 8.3 & 19.2 & 0.1 & 1.4 & 0.0 & 40.0 & 28.6 & 0.8 & 8.4 & 0.6 \\
\hline Yaan & 53.5 & 9.3 & 5.5 & 0.0 & 17.6 & 1.2 & 0.0 & 0.0 & 0.0 & 9.1 & $\begin{array}{l}3.0 \\
3.6\end{array}$ & 9.5 & $\begin{array}{l}.1 \\
1.0\end{array}$ & $\begin{array}{l}1.4 \\
0.5\end{array}$ & 0.5 & 4.6 & $\begin{array}{l}20.0 \\
0.0\end{array}$ & $\begin{array}{l}.0 \\
0.8\end{array}$ & $\begin{array}{l}0.4 \\
77.6\end{array}$ & 8.2 \\
\hline Ziyang & 142.0 & 0.0 & 0.8 & 0.0 & 0.3 & 0.1 & 0.0 & 0.0 & 0.0 & 26.0 & 7.5 & 30.5 & 0.0 & 2.3 & 0.0 & 0.1 & 4.3 & 0.0 & 23.2 & 0.3 \\
\hline Total & 2655.7 & 631.3 & 138.9 & 223.8 & 607.6 & 19.5 & 183.7 & 6.5 & 311.5 & 475.1 & 165.8 & 427.1 & 26.8 & 47.2 & 1.8 & 276.1 & 148.2 & 4154.9 & 1402.3 & 44.9 \\
\hline
\end{tabular}




\subsection{Uncertainty Analysis Results}

For the activity data, CVs from different sectors are between $5 \%$ to $30 \%$, while CVs for the emission factors related coal, oil, and natural gas are $3 \%, 1 \%$ and $2 \%$, respectively. The simulation results show that $97.5 \%$ of the uncertainty in 15 cities (central estimated value of $\pm 47.5 \%$ confidence interval) decreased to a range of $-5.6-7.8 \%$.

\subsection{Examination of the Achievement of Emission Reduction Goal in Regions and Cities}

In the "Paris Agreement", China proposed an emission reduction goal to reduce 60-65\% of their emission intensity by 2030 compared to the level in 2005 [53]. Based on the assumption of a moving average in regional $\mathrm{CO}_{2}$ emission amounts and GDP growth, the emission reduction in Eastern, Central, And Western China (including several key cities in Sichuan) in 2025 and 2030 are estimated. This analysis will explain if the reduction goal can be achieved with the current speed, and if the reduction speed needs to be raised for achieving this goal. The results are shown in Table 4.

Table 4. Forecast of the carbon emission intensity.

\begin{tabular}{ccccccccc}
\hline Tons/CNY 10 & $\mathbf{2 0 0 5}$ & $\mathbf{2 0 1 0}$ & $\mathbf{2 0 1 5}$ & $\mathbf{2 0 2 0}$ & $\mathbf{2 0 2 5}$ & $\mathbf{2 0 3 0}$ & $\begin{array}{c}\text { Actual Emission } \\
\text { Reduction }\end{array}$ & $\begin{array}{c}\text { Target Emission } \\
\text { Reduction }\end{array}$ \\
\hline Eastern Region & 2.25 & 1.50 & 1.03 & 0.92 & 0.85 & 0.83 & $63.15 \%$ & $60-65 \%$ \\
China Central & 3.34 & 2.21 & 1.44 & 1.33 & 1.29 & 1.32 & $60.43 \%$ & $60-65 \%$ \\
Western Region & 3.66 & 2.61 & 1.89 & 1.93 & 2.05 & 2.29 & $37.50 \%$ & $60-65 \%$ \\
Chengdu & 0.88 & 0.73 & 0.44 & 0.49 & 0.57 & 0.67 & $23.86 \%$ & $60-65 \%$ \\
Mianyang & 3.36 & 1.51 & 0.72 & 0.55 & 0.44 & 0.38 & $88.69 \%$ & $60-65 \%$ \\
Panzhihua & 20.52 & 22.01 & 9.12 & 8.85 & 8.99 & 9.46 & $53.90 \%$ & $60-65 \%$ \\
\hline
\end{tabular}

According to the results, Eastern and Western China will be able to reach the national overall reduction goal by 2030, although this will be more challenging for Western China. The total reduction in emission intensity in Western China will be $37.50 \%$ according to this reduction speed, falling far from a goal of at least a $60 \%$ reduction. Within Sichuan Province, cities also display different results. Mianyang will be able to reach the goal with a reduction in its emission intensity greater than $88.69 \%$, while Chengdu cannot achieve the goal, partially because it has always had a lower level of intensity which is hard to reduce. The truly confusing cities, such as Panzhihua, suffer a higher level of intensity. However, they have not found nor implemented useful actions to stop failing. Therefore, for achieving the reduction goals in Western China, at first, analyzing the carbon intensity from the absolute value and relative value would provide a fuller picture. Then, paying more attention to the cities which display higher carbon intensities, by investigating the industrial structures, dominant industries and making more city-level reduction policies with targeted or specific purposes. Finally, for maintaining the balance between economic growth and the transformation to a low-carbon society, dynamic control is necessary, especially for city-level governments.

\subsection{Discussion}

Since energy consumption data at the city-level and sub-sector level are difficult to obtain, data availability makes this study focus on 15 cities in Sichuan Province. By including all critical cities in Sichuan, such as Chengdu, Panzhihua, and Mianyang, we can attain the main characteristics of this province and provide some typical results in order to inform some policies or strategies with respect to economic development and the reduction of $\mathrm{CO}_{2}$ emissions.

As shown in Sections 3.1 and 3.2, the overall emissions of 15 cities snowballed in 2007-2012 and peaked in 2012. However, the carbon intensity reached a peak of 66.47 tons $/ 10^{4}$ CNY in 2007 and then dropped to 28.05 tons $/ 10^{4} \mathrm{CNY}$. The average emission intensity of 15 cities in 2015 was 1.87 tons $/ 10^{4} \mathrm{CNY}$, demonstrating that the emission intensity in Western China is higher than average city-level in China. Coal and coal-related products (raw coal, clean coal, other coal washing, briquette, 
and coke) are the most consumed types of energy. They are also the main energy emitting $\mathrm{CO}_{2}$ in Sichuan. The heavy industries, such as, smelting and pressing of ferrous metals, coal mining and dressing, nonmetal mineral products, production and supply of electric power, steam and hot water are the sectors contributed the most to $\mathrm{CO}_{2}$ emissions during the study period, accounting for $17.86 \%$, $15.82 \%, 14.26 \%$, and $14.17 \%$, respectively. It also proves that Sichuan Province is still in the middle stage of industrialization, and the secondary industry dominates its economic structure. Furthermore, the proportion of GDP supports the economic structure of Sichuan where the primary, secondary and tertiary industries constitute $12.24 \%, 44.08 \%$ and $43.68 \%$, respectively, in 2015 . Thus, it is unsurprising that the secondary industry's carbon dioxide emissions accounted for the largest share of $88.73 \%$, and that Sichuan needs to mainly focus on how to maintain secondary industry development and lower emissions by exploiting fully the use of the hydropower.

As mentioned in the supporting analyses in Sections 3.2 and 3.3, in Sichuan Province, hydropower generation occupies a large share of the total power supply. In 2015, the generation of hydropower was 276.74 billion kWh, occupying $86.3 \%$ of the total electricity supply in Sichuan, and installed capacity is 69.39 million $\mathrm{kW}$, representing $80.01 \%$ of the province-level capacity [54]. As we all know, optimizing the structure of energy supply by increasing the share of clean energy is crucial to low-carbon development [55-58]. Sichuan has been in the leading position to develop clean energy. The expansion of hydropower capacity has led to a sharp decrease in the share of $\mathrm{CO}_{2}$ emissions in the electricity supply sector, from 14.5\% in 2003 (a historical peak level) to $4.8 \%$ in 2015 and emission amounts also declining from $9.85 \mathrm{mt}$ in 2010 to $3.56 \mathrm{mt}$ in 2015. Such great achievement of $\mathrm{CO}_{2}$ emission reduction can be important references to the low-carbon development in the regions with the potential of expanding hydropower capacity. More specifically, the Western region of China holds relatively more advantages with respect to natural conditions for the development of clean energy, including hydropower, wind power, solar power, and biomass power generation. For energy policymakers, the re-structuring of the energy supply and the promotion of low-carbon development in the Western region of China does not only benefit local producers and consumers, but with the increasingly frequent electricity transmission between different grids in China, the whole country, and even other countries affected by the supply of electricity from China, could benefit in terms of $\mathrm{CO}_{2}$ emission mitigation.

\section{Conclusions}

This study, based on the IPCC regional emission method, is the first research performed on carbon dioxide accounting for $15 \mathrm{key}$ cities in Sichuan Province representing Western China, and is consistent with the national and provincial emission inventories. The $\mathrm{CO}_{2}$ emissions inventories consisted of 17 fossil fuels, 47 socioeconomic sectors and seven industrial processes to reveal useful information in order to determine the city's major emission contributors and different emission characteristics. Therefore, this study can provide an opportunity to analyze the features of emissions in 15 cities in Sichuan Province, provide key data to support the formulation of low-carbon policies in Sichuan Province, and provide a reference for the development and implementation of low-carbon development strategies in other parts of the Western region. It is useful for the advancement of China's low carbon development process.

The total carbon dioxide emissions in 15 cities increased rapidly from 2007 to 2012, with an average growth rate of $12.31 \%$ and peaked in 2012 with 406.23 million tons. From 2006 to 2015, the total emissions of Sichuan Province accounted for $14.92 \%$ of the western region, and the emission intensity and emissions per capita were 1.42 and 1.24 times of the national average, respectively. For sector sources, the secondary industry contributed $88.73 \%$ in total carbon dioxide emissions and the tertiary industry contributed $10.52 \%$. In the secondary industry, metals and energy-related heavy industry accounts the majority parts. During the study period, raw coal was the highest contributor in all energy categories (43.73\%), reaching a peak of $199.78 \mathrm{Mt}$ in 2012 . It is worthy to research how to decrease the high emissions from coal by way of more targeted policy control or market incentives. 
Sichuan Province is shifting from an industrial economy to a service economy, and carbon dioxide emissions in most cities have peaked in 2011-2013 and moved to a stage of decline.

It is Sichuan Province that is China's leader in economic development in the Western region, especially under the "Western Development" and "One Belt, One Road" initiatives. It also plays an essential role in promoting low carbon and sustainable development in the Western region. Due to the economic structure transitioning from the secondary industry to the tertiary industry, and the advanced development of clean energy power generation, at present, the overall emissions in the main cities have begun to decline. In order to continue to maintain a low-carbon development trend in Sichuan Province, government departments should formulate active and effective development strategies, such as increasing the proportion of clean energy to replace fossil energy, optimizing the industrial structure, and enhancing processing techniques in order to promote regional low-carbon economic development.

Unfortunately, there are still some limitations to this study. The missing data of energy consumption in some cities lead the carbon emission incomplete. In the meantime, we choose 15 cities to make this analysis, also partially due to the data quality issues or relatively low levels of emission. Furthermore, even though we mentioned a large amount of clean energy consumption in Sichuan Province, such as hydropower generation, we believe the continuous development of these clean energy resources will have a positive impact on regional carbon emission reduction. This study does not consider the contribution of hydropower development to the greenhouse effect in Sichuan Province and nearby regions. We will improve the above shortcomings and limitations in future work, and explore the impacts of emission reduction approaches and energy footprints on the emission reduction potential of Western China.

Supplementary Materials: The following are available online at http://www.mdpi.com/1996-1073/12/10/2025/s1.

Author Contributions: Conceptualization, Y.J. and X.Z.; Data curation, J.W., L.C. (Liu Chen) and L.C. (Lu Chen); Formal analysis, J.W.; Funding acquisition, M.W. and L.X.; Methodology, J.W. and Y.J.; Supervision, M.W. and L.X.; Writing —Original Draft, J.W., L.C. (Liu Chen) and L.C. (Lu Chen); Writing-Review \& Editing, Y.J. and X.Z.

Funding: This research is supported by funding from the National Social Science Foundation of China (17BGL147).

Conflicts of Interest: The authors declare no conflict of interest.

\section{References}

1. Lin, J.Y.; Liu, Y.; Meng, F.X.; Cui, S.H.; Xu, L.L. Using hybrid method to evaluate carbon footprint of Xiamen City, China. Energy Policy 2013, 58, 220-227. [CrossRef]

2. Lin, B.Q.; Ahmad, I. Analysis of energy related carbon dioxide emission and reduction potential in Pakistan. J. Clean. Prod. 2017, 143, 278-287. [CrossRef]

3. Carrie, M.; Lee, P.E. What Impact can Local Economic Development in Cities Have on Global GHG Emissions? Assessing the Evidence; Cities: Impact on Global GHG Emissions; Environment Institute: Stockholm, Sweden, 2014.

4. Guan, D.; Mi, Z.; Liu, Z.; Liu, J.; Viguié, V.; Fromer, N.; Wang, Y. Cities: The core of climate change mitigation. J. Clean. Prod. 2019, 207, 582-589.

5. Shan, Y.; Guan, D.; Liu, J.; Mi, Z.; Liu, Z.; Liu, J.; Schroeder, H.; Cai, B.; Chen, Y.; Shao, S.; et al. Methodology and applications of city level $\mathrm{CO}_{2}$ emission accounts in China. J. Clean. Prod. 2017, 161, 1215-1225. [CrossRef]

6. Chen, S.; Chen, B.; Su, M. Nonzero-sum relationships in mitigating urban carbon emissions: A dynamic network simulation. Environ. Sci. Technol. 2015, 49, 11594-11603. [CrossRef]

7. Mi, Z.F.; Zhang, Y.K.; Guan, D.B.; Shan, Y.L.; Liu, Z.; Cong, R.G.; Yuan, X.-C.; Wei, Y.-M. Consumption-based emission accounting for Chinese cities. Appl. Energy 2016, 184, 1073-1081. [CrossRef]

8. Mi, Z.F.; Meng, J.; Guan, D.B.; Shan, Y.L.; Liu, Z.; Wang, Y.; Feng, K.; Wei, Y.-M. Pattern changes in determinants of Chinese emissions. Environ. Res. Lett. 2017, 12. [CrossRef]

9. IEA. World Energy Outlook Special Report 2013; International Energy Agency: Paris, France, 2014.

10. Yang, Q.; Guo, S.; Yuan, W.H.; Shen, Q.P.; Wang, X.H.; Wu, T.H.; Chen, Z.-M.; Alsaedi, A.; Hayat, T. Energy-dominated carbon metabolism: A case study of Hubei province, China. Ecol. Inf. 2015, 26, 85-92. [CrossRef] 
11. Wrigley, E. Energy and the Industrial Revolution in England; Cambridge University Press: Cambridge, UK, 2010.

12. Stern, D.I.; Kander, A. The role of energy in the industrial revolution and modern economic growth. SSRN Electron. J. 2012, 33, 125-152. [CrossRef]

13. NBS. Energy Statistical Yearbook 2001-2017; China Statistics Press: Beijing, China, 2001-2017.

14. China Emission Accounts \& Datasets. 2018. Available online: http://www.ceads.net/ (accessed on 26 May 2019).

15. IEA. Global Energy \& $\mathrm{CO}_{2}$ Status Report 2017; International Energy Agency: Paris, France, 2018.

16. IPCC. Climate Change 2014 _IPCC Fifth Assessment Report; Cambridge University Press: Cambridge, UK, 2014.

17. IEA. World Energy Outlook 2008; International Energy Agency: Paris, France, 2008.

18. Shan, Y.; Guan, D.; Hubacek, K.; Zheng, B.; Davis, S.J.; Jia, L.; Liu, J.; Liu, Z.; Fromer, N.; Mi, Z.; et al. City-level climate change mitigation in China. Sci. Adv. 2018, 4, eaaq0390. [CrossRef]

19. Zhang, B.; Qiao, H.; Chen, Z.; Chen, B. Growth in embodied energy transfers via China'sdomestic trade: Evidence from multi-regional input-output analysis. Appl. Energy 2016, 184, 1093-1095. [CrossRef]

20. Rosenzweig, C.; Solecki, W.; Hammer, S.A.; Mehrotra, S. Cities lead the way in climate-change action. Nature 2010, 467, 909. [CrossRef]

21. Xi, F.M.; Geng, Y.; Chen, X.D.; Zhang, Y.S.; Wang, X.; Xue, B.; Dong, H.; Liu, Z.; Ren, W.; Fujita, T.; et al. Contributing to local policy making on GHG emission reduction through inventorying and attribution: A case study of Shenyang, China. Energy Policy 2011, 39, 5999-6010. [CrossRef]

22. IEA. Energy Technology Perspectives 2016 Towards Sustainable Urban Energy Systems; International Energy Agency: Paris, France, 2016.

23. Shan, Y.; Guan, D.; Zheng, H.; Ou, J.; Li, Y.; Meng, J.; Mi, Z.; Liu, Z.; Zhang, Q. China $\mathrm{CO}_{2}$ emission accounts 1997-2015. Sci. Data 2018, 5, 170201. [CrossRef] [PubMed]

24. Zhou, Y.; Shan, Y.; Liu, G.S.; Guan, D.B. Emissions and low-carbon development in Guangdong-Hong Kong-Macao Greater Bay Area cities and their surroundings. Appl. Energy 2018, 228, 1683-1692. [CrossRef]

25. Oh, B.K.; Choi, S.W.; Park, H.S. Influence of variations in $\mathrm{CO}_{2}$ emission data upon environmental impact of building construction. J. Clean. Prod. 2017, 140, 1194-1203. [CrossRef]

26. Khanna, N.; Fridley, D.; Hong, L.X. China's pilot low-carbon city initiative: A comparative assessment of national goals and local plans. Sustain. Cities Soc. 2014, 12, 110-121. [CrossRef]

27. Geng, Y.; Zhao, H.Y.; Liu, Z.; Xue, B.; Fujita, T.; Xi, F.M. Exploring driving factors of energy-related $\mathrm{CO}_{2}$ emissions in Chinese provinces: A case of Liaoning. Energy Policy 2013, 60, 820-826. [CrossRef]

28. Shan, Y.L.; Liu, J.H.; Liu, Z.; Xu, X.; Shao, S.; Wang, P.; Guan, D. New provincial $\mathrm{CO}_{2}$ emission inventories in China based on apparent energy consumption data and updated emission factors. Appl. Energy 2016, 184, 742-750. [CrossRef]

29. Shan, Y.L.; Liu, Z.; Guan, D.B. $\mathrm{CO}_{2}$ emissions from China's lime industry. Appl. Energy 2016, 166, $245-252$. [CrossRef]

30. Gao, C.C.; Liu, Y.H.; Jin, J.; Wei, T.Y.; Zhang, J.Y.; Zhu, L.Z. Driving forces in energy-related carbon dioxide emissions in east and south coastal China: Commonality and variations. J. Clean. Prod. 2016, 135, 240-250. [CrossRef]

31. Xu, S.C.; Han, H.M.; Zhang, W.W.; Zhang, Q.-Q.; Long, R.-Y.; Chen, H.; He, Z.-X. Analysis of regional contributions to the national carbon intensity in China in different Five-Year Plan periods. J. Clean. Prod. 2017, 145, 209-220. [CrossRef]

32. Wang, S.; Ma, Y. Influencing factors and regional discrepancies of the efficiency of carbon dioxide emissions in Jiangsu, China. Ecol. Indic. 2018, 90, 460-468. [CrossRef]

33. Shen, L.; Wu, Y.; Lou, Y.; Zeng, D.; Shuai, C.; Song, X. What drives the carbon emission in the Chinese cities?-A case of pilot low carbon city of Beijing. J. Clean. Prod. 2018, 174, 343-354. [CrossRef]

34. Jia, J.; Gong, Z.; Xie, D.; Chen, J.; Chen, C. Analysis of drivers and policy implications of carbon dioxide emissions of industrial energy consumption in an underdeveloped city: The case of Nanchang, China. J. Clean. Prod. 2018, 183, 843-857. [CrossRef]

35. Lee, T.D.; van de Meene, S.S. Comparative studies of urban climate co-benefits in Asian cities: An analysis of relationships between $\mathrm{CO}_{2}$ emissions and environmental indicators. J. Clean. Prod. 2013, 58, 15-24. [CrossRef]

36. Wang, Q.; Zhao, M.; Li, R. Decoupling sectoral economic output from carbon emissions on city level: A comparative study of Beijing and Shanghai, China. J. Clean. Prod. 2019, 209, 126-133. [CrossRef] 
37. Dhakal, S. Urban energy use and carbon emissions from cities in China and policy implications. Energy Policy 2009, 37, 4208-4219. [CrossRef]

38. Liu, Z.; Liang, S.; Geng, Y.; Xue, B.; Xi, F.; Pan, Y.; Zhang, T.; Fujita, T. Features, trajectories and driving forces for energy-related GHG emissions from Chinese mega cites: The case of Beijing, Tianjin, Shanghai and Chongqing. Energy 2012, 37, 245-254. [CrossRef]

39. Sugar, L.; Kennedy, C.; Leman, E. Greenhouse gas emissions from chinese cities. J. Ind. Ecol. 2012, 16, 552-563. [CrossRef]

40. Feng, K.; Davis, S.J.; Sun, L.; Li, X.; Guan, D.; Liu, W.; Hubacek, K. Outsourcing $\mathrm{CO}_{2}$ within China. Proceedings of the National Academy of Sciences. Sustain. Sci. 2013, 110, 11654-11659.

41. IPCC. IPCC Guidelines for National Greenhouse Gas Inventories; Institute for Global Environmental Strategies (IGES): Hayama, Japan, 2006.

42. NDRC. First Biennial Update Report on Climate Change; NDRC: Beijing, China, 2016.

43. Peters, G.P.; Weber, C.; Liu, J. Construction of Chinese energy and emissions inventory. Norwegian University of Science and Technology. Acad. Med. J. Assoc. Am. Med. Coll. 2006, 69, 703-710.

44. GAQSIQ. General Administration of Quality Supervision (GB/T 4754-2011); Inspection and Quarantine of the People's Republic of China: Beijing, China, 2011.

45. NDRC. Initial National Communication on Climate Change; China Planning Press: Beijing, China, 2004.

46. NDRC. The People's Republic of China Second National Communication on Climate Change; NDRC: Beijing, China, 2012.

47. Liu, Z.; Guan, D.; Wei, W.; Davis, S.J.; Ciais, P.; Bai, J.; Peng, S.; Zhang, Q.; Hubacek, K.; Marland, G.; et al. Reduced carbon emission estimates from fossil fuel combustion and cement production in China. Nature 2015, 524, 335-338. [CrossRef]

48. Zhou, Y.; Li, Y.P.; Huang, G.H. Planning sustainable electric-power system with carbon emission abatement through CDM under uncertainty. Appl. Energy 2015, 140, 350-364. [CrossRef]

49. Zhou, Y.; Huang, G.; Zhu, H.; Li, Z.; Chen, J. A factorial dual-objective rural environmental management model. J. Clean. Prod. 2016, 124, 204-216. [CrossRef]

50. Zhou, Y.; Huang, G.H.; Yang, B. Water resources management under multi-parameter interactions: A factorial multi-stage stochastic programming approach. Omega 2013, 41, 559-573. [CrossRef]

51. Zhao, Y.; Wang, S.; Duan, L.; Lei, Y.; Cao, P.; Gao, J. Primary air pollutant emissions of coal-fired power plants in China: Current status and future prediction. Atmos. Environ. 2008, 42, 8442-8452. [CrossRef]

52. Wu, Y.; Streets, D.; Wang, S.; Hao, J. Uncertainties in estimating mercury emissions from coal-fired power plan. Atmos. Chem. Phys. 2010, 10, 2937-2947. [CrossRef]

53. UNFCCC. United Nations Framework Convention on Climate Change (UNFCCC); Paris Agreement: New York, NY, USA, 2015.

54. Sichuan Provincial People's Government. Sichuan created the National Clean Energy Demonstration Province; Sichuan Provincial People's Government: Chengdu, China, 2016.

55. Urban, F. Climate-Change Mitigation Revisited: Low-carbon energy transitions for China and India. Dev. Policy Rev. 2009, 27, 693-715. [CrossRef]

56. Li, H.Q.; Wang, L.M.; Shen, L.; Chen, F.N. Study of the potential of low carbon energy development and its contribution to realize the reduction target of carbon intensity in China. Energy Policy 2012, 41, 393-401. [CrossRef]

57. Liu, Q.; Chen, Y.; Tian, C.; Zheng, X.Q.; Li, J.F. Strategic deliberation on development of low-carbon energy system in China. Adv. Clim. Chang. Res. 2016, 7, 26-34. [CrossRef]

58. Hu, H.; Xie, N.; Fang, D.B.; Zhang, X.L. The role of renewable energy consumption and commercial services trade in carbon dioxide reduction: Evidence from 25 developing countries. Appl. Energy 2018, 211, 229-1244. [CrossRef]

(C) 2019 by the authors. Licensee MDPI, Basel, Switzerland. This article is an open access article distributed under the terms and conditions of the Creative Commons Attribution (CC BY) license (http://creativecommons.org/licenses/by/4.0/). 